\title{
Luces y sombras del ejercicio del test de sustitución en Colombia**
}

\section{Lights and Shadows from the Exercise of the Substitution Test in Colombia}

RESUMEN

Se adelanta un balance general sobre el ejercicio del control de constitucionalidad sobre los denominados "vicios de competencia", por parte de la Corte Constitucional colombiana, a lo largo de casi dos décadas. En tal sentido, se plantea que, contrario a lo que podría pensarse, la realización del referido control de constitucionalidad no ha inhibido el espíritu reformista del Congreso de la República. Sin embargo, paradójicamente, algunos fallos de la Corte Constitucional, en especial referidos a temas de estructura del Estado (v. gr., administración de justicia), pueden introducir algunas rigideces inconvenientes al Texto Fundamental de 1991.

Por último, se pretende demostrar que la realización del test de sustitución resultó ser extremadamente severo en materia de implementación del Acuerdo de Paz, lo cual no deja de ser sorprendente, dado el carácter temporal de estas reformas constitucionales.

PALABRAS CLAVE

Sustitución de la Constitución, control de constitucionalidad por vicios de competencia, supraconstitucionalidad, control de constitucionalidad sobre el proceso de paz, cláusulas intangibles.

\section{ABSTRACT}

The article provides a balance on the exercise of the constitutional control over the so-called "substantive grounds" by the Colombian Constitutional Court, over almost two decades.

* Abogado, Universidad Externado de Colombia. Máster en Derechos Humanos, Universidad de París x Nanterre. Doctor en Derecho, Universidad de Salamanca. Magistrado del Tribunal Especial para la Paz. Presidente de la Sección de Primera Instancia para Casos de Ausencia de Reconocimiento. Colombia. Docente, Universidad Externado de Colombia. Correo electrónico alejandro.ramelli70@gmail.com. oRCID: https://orcid.org/0000-0002-3846-2708.

** Recibido el 26 de mayo del 2020, aprobado el 31 de agosto del 2020.

Para citar el artículo: Luces y sombras del ejercicio del test de sustitución en Colombia. En Revista Derecho del Estado, Universidad Externado de Colombia. N. ${ }^{\circ} 48$, enero-abril de 2021,31-50. DOI: https://doi.org/10.18601/01229893.n48.02 
In this sense, it is suggested that, contrary to what might be thought, the performance of the aforementioned constitutionality control has not inhibited the reformist spirit of the Congress of the Republic. However, paradoxically, some rulings of the Constitutional Court, specially referring to matters of State structure (e.g., administration of justice), may introduce some inconvenient rigidities to the Basic Text of 1991.

Finally, it is intended to demonstrate that the performance of the substitution test turned out to be extremely severe in terms of the implementation of the Peace Agreement, which is still surprising, given the temporary nature of these constitutional reforms.

\section{KEYWORDS}

Substitution of the Constitution, control of constitutionality due to substantive grounds, supraconstitutionality, control of constitutionality over the peace process, intangible clauses.

\section{SUMARIO}

Introducción. I. Fundamentos del control constitucional por vicios de competencia en materia de reformas a la Carta Política. II. Identificación y concreción de los "elementos definitorios" de la Constitución de 1991. III. El test de sustitución. Iv. Casos en que la premisa mayor son estándares internacionales: ¿una supraconstitucionalidad negada? v. El test de sustitución frente al Acuerdo Final. Conclusiones. Bibliografía

\section{INTRODUCCIÓN}

El objeto del presente artículo apunta a realizar un balance y señalar algunos retos en relación con el ejercicio del control constitucional sobre los denominados "vicios de competencia", facultad que la Corte Constitucional viene ejerciendo desde la sentencia C-551 de 2003, la cual le permite ir más allá del clásico examen de los vicios de procedimiento en materia de reformas constitucionales.

En tal sentido, pretendo demostrar: (1) que el ejercicio del test de sustitución, contrario a lo que se pensó en su momento, no ha inhibido el espíritu reformista del Congreso de la República, lo cual muestra la existencia de una preocupante tendencia hacia la constitucionalización de asuntos que bien podrían regularse por vía legal; (2) que la praxis del test de sustitución para asuntos diferentes a la defensa de los derechos fundamentales $(v . g r$. , tribunal de aforados, administración de la Rama Judicial, etcétera) genera unas perversas rigideces en la estructura del Estado colombiano (3); que si bien la Corte Constitucional ha insistido expresamente en la inexistencia de un paradigma 
de supraconstitucionalidad en materia de relaciones entre la Carta Política y los tratados internacionales sobre derechos humanos, la manera como se construye la premisa mayor del test de sustitución pone de presente lo contrario: la prevalencia de estándares internacionales sobre las normas constitucionales; y (4) que el ejercicio del test de sustitución resultó ser particularmente severo en materia de normas de implementación del Acuerdo Final, lo cual no deja de ser paradójico tomando en cuenta su naturaleza transitoria, tratarse de un instrumento de concreción del derecho fundamental a la paz y la inexistencia de cargos de inconstitucionalidad.

Sin lugar a dudas, la fundamentación, el contenido, el alcance y los límites al control judicial sobre los textos reformatorios de la Constitución son temas de la mayor controversia en el derecho comparado (unconstitutional constitutional amendments $^{1}$ ) y colombiano ${ }^{2}$. Se trata de un tema que se inscribe en la clásica tensión existente entre la democracia de mayorías y la democracia constitucional.

En el derecho comparado, un antecedente fundamental en la construcción de una teoría general sobre los límites materiales al poder de reforma constitucional se encuentra en el fallo Golaknath vs. State of Punjab proferido el 27 de febrero de 1967 por la Corte Suprema de Justicia de la India ${ }^{3}$.

El principal problema jurídico consistió en determinar si el Parlamento contaba con la competencia para enmendar los derechos fundamentales consagrados en la parte III de la Constitución ${ }^{4}$.

La mayoría de integrantes de la Corte consideró que si bien el Parlamento contaba con la facultad para reformar la Constitución (art. 368), dicha competencia no era absoluta, por cuanto resultaba esencial preservar "los ideales originales previstos por los creadores de la Constitución"5.

El 24 de abril de 1973, la Corte Suprema de la India en el caso Kesavananda Bharati vs. State of Kerala ${ }^{6}$ sostuvo, en una decisión dividida, que la existencia de un conjunto de principios inviolables implícitos (basic structure

1 Especialmente RozNAI, Y YNIV, "Unconstitutional constitutional amendments: The Limits of Amendment Powers, Cambridge, 2017, y RozNAI, YANIV, "The migration and success of a constitutional idea", en: American Journal of Comparative Law, Vol. 61, n. ${ }^{\circ}$ 3, 2013.

2 Véase, por ejemplo, Ramírez Cleves, Gonzalo, Límites a la reforma constitucional en Colombia: el concepto de Constitución como fundamento de la restricción, Bogotá, Universidad Externado de Colombia, 2005, y Ramírez Cleves, Gonzalo, "La inconstitucionalidad de las reformas constitucionales en Colombia: tensión entre democracia de mayorías y democracia constitucional", en La reforma constitucional y su problemática en el derecho comparado (ed. Víctor Alejandro Wong, Carolina León, Juan Luis Sosa), México, edit. VLex, 2017.

3 Corte Suprema de la India, asunto Golaknath vs. State of Punjab sentencia del 27 de febrero de 1967 (1967) AIR 1643, 2 mil SCR (2) 76.

4 Diva RaI, Golaknath, I.C v State of Punjab (1967): Overview and Analysis, 2019.

5 Ibídem.

6 Corte Suprema de la India, asunto Kesavaranda Bharati vs. State of Kerala, sentencia del 24 de abril de 1973,(1973) 4 sCC 225. 
doctrine), contenidos en la Constitución de 1950, no podía ser reformada por el Parlamento.

En 1976 se aprobó una enmienda constitucional, encaminada a evitar que los jueces constitucionales continuaran ejerciendo tal facultad, modificación que, a su vez, fue declarada inconstitucional en 1980, en el asunto Minerva Mills vs. Union of India, por cuanto hace parte de la estructura básica de la Carta Política, la competencia de los jueces para dejar sin efectos una enmienda que viole los elementos implícitos ${ }^{7}$.

Más recientemente, en 2015, en el asunto Supreme Court Advocates on Record Association vs. Union of India, se consideró que los textos de varias reformas constitucionales afectaban la estructura básica de la Constitución, en especial la cláusula del Estado social de derecho, la dignidad humana y la independencia judicial ${ }^{8}$.

La jurisprudencia de la Corte Suprema de la India, con el correr de los años, ha considerado que integran estructura básica de la Constitución principios tales como: (1) la supremacía constitucional; (2) el carácter secular de la Carta Política; (3) la separación de poderes; (4) la integridad y unidad de la nación; (5) la forma democrática y republicana de gobierno; y (6) la soberanía nacional ${ }^{9}$.

En el año 2008, la Corte Constitucional de Turquía anuló una enmienda a la Carta Política de 1982, mediante la cual se introducían algunas modificaciones a dos cláusulas de derechos fundamentales: los artículos 10 (igualdad ante la ley) y 42 (derecho a la educación). El fundamento de la decisión fue: desconocimiento del principio esencial de República laica ${ }^{10}$.

Los anteriores ejemplos prueban la existencia de una tensión constante entre el principio democrático -fundado en la regla de la mayoría y en la necesidad de ajustar la Constitución a las nuevas realidades económicas, políticas y culturales de una sociedad- y la preservación de ciertos elementos fundantes de un Estado social de derecho, en especial la Carta de Derechos Fundamentales.

Los defensores del principio democrático sostienen que los autores de un Texto Fundamental no pueden amarrar ad infinitum a las generaciones futuras. En palabras de Thomas Jefferson, "la Tierra pertenece a las generaciones vivientes" ("the Earth belongs to the living"), y por ende, "es absurdo que los muertos puedan, mediante la Constitución, imponer su voluntad a los

7 Benítez Rojas, Vicente, Constitución popular, no judicial. Una teoría democrática del control de constitucionalidad de las reformas a la Constitución en Colombia, Bogotá, TemisUniversidad de La Sabana, 2014, p. 2.

8 Corte Suprema de la India, sentencia del 15 de octubre de 2015, writ petition (Civil), n. ${ }^{\circ} 3,2015$.

9 Diva RaI, ob.cit.

10 KaBOGLu, IBRAHIM, "Le contrôle jurisdictionnel des amendements constitutionnels en Turquie", Les cahiers du Constitutionnel, París, 2009, p. 39. 
vivos", reflexiones que quedaron consignadas en el artículo 28 de la Constitución francesa de 1793: "[U]n pueblo tiene siempre el derecho a revisar, reformar y cambiar su Constitución. Una generación no puede someter a las generaciones futuras" ${ }^{11}$.

Agregan, en los términos clásicos de El Federalista, que "La imperfección humana no puede producir obras perfectas. El resultado de las deliberaciones de un cuerpo colectivo debe participar forzosamente de los errores y prejuicios, así como del buen sentido y la sabiduría de los individuos que lo integran"12. En palabras de Carlos Santiago Nino, las constituciones se asemejan a catedrales en permanente construcción.

Desde esta perspectiva, los diversos mecanismos que prevén las constituciones actuales para su reforma aseguran que ciertos grupos políticos puedan canalizar, por medios pacíficos, sus aspiraciones ideológicas. Las denominadas "cláusulas pétreas" carecerían de sentido, por cuanto las mayorías terminarían por acudir a vías no institucionales, con miras a modificar, corregir o actualizar un modelo constitucional vigente ${ }^{13}$. Adicionalmente, dicha Carta Política no resultaría ser verdaderamente democrática, "puesto que aunque formalmente se exprese que la soberanía está en el pueblo, se impide su reforma mediante canales institucionales democráticos como el Congreso" 14 .

En la otra orilla, los defensores de la prevalencia de ciertos valores y principios esenciales frente a las decisiones mayoritarias, en especial en materia de derechos fundamentales, apoyan sus tesis en argumentos de diversa naturaleza:

En algunos países, como sucede en Alemania, la existencia de cláusulas pétreas, incluso implícitas, responde a motivos históricos. El temor del regreso a un sistema autocrático de gobierno, amén de encontrarse ese país en 1949 con una soberanía territorial restringida, condujo a la inclusión en la Ley Fundamental de Bonn, de un conjunto de límites al poder de reforma constitucional, previstos en el artículo 79.3, entre ellos: la organización de la Federación en Länder, el principio de la participación de los Länder en la legislación y los "principios enunciados en los artículos 1 y 20" (la dignidad humana, derechos fundamentales y el estado social y democrático de derecho). Otro tanto puede decirse de Italia con el fin de fascismo que estableció como cláusula pétrea la prohibición de modificar el carácter republicano del Estado en el artículo en el artículo 139 de la Constitución.

11 Ramírez Cleves, Gonzalo, Los límites a la reforma constitucional y las garantías-límites del poder constituyente: los derechos fundamentales como paradigma, Bogotá, Universidad Externado de Colombia, 2003, p. 44.

12 Hamilton, Alexander; Madison, James y Jay, John, El Federalista, México, Fondo de Cultura Económica, 1994.

13 Ackerman, Bruce, Constitutional Politics. Constitutional Law, The Yale Law Journal, núm. 99, 1989.

14 Benítez, Vicente, Jueces y democracia: entre Ulises y los cantos de sirenas, Revista de la Facultad de Derecho y Ciencias Políticas, 2012. 
Algunos autores, como Elster ${ }^{15}$, comparan los referidos límites al clásico mito de Ulises: el pueblo, ante la incertidumbre del futuro, decide "atarse al mástil", y preservar los elementos básicos de un Estado social de derecho, ante las embestidas de las mayorías. En este símil, los tribunales constituciones desempeñan el papel de marineros, evitando que su capitán se desate y conduzca la nave del Estado hacia el abismo.

Un tercer argumento apunta a que el principio democrático no puede ser comprendido en términos meramente procedimentales. De allí que cuando un tribunal constitucional declara sin efectos una enmienda contraria a ciertos principios fundantes de un Estado social de derecho, no está frustrando el querer de las mayorías, sino amparando a los derechos de las minorías.

Así las cosas, en líneas generales, el ejercicio del test de sustitución en Colombia ha aportado a los grandes debates teóricos acerca de la existencia de límites al poder de reforma de la Constitución, lo cual no ha sido ajeno a las críticas acerca del activismo judicial y al desbordamiento de competencias por parte de un órgano igualmente constituido.

\section{FUNDAMENTOS DEL CONTROL CONSTITUCIONAL POR VICIOS \\ DE COMPETENCIA EN MATERIA DE REFORMAS A LA CARTA POLÍTICA}

Uno de los mayores retos que ha asumido la Corte Constitucional ha sido justificar la atribución del control de constitucionalidad por vicios de competencia en materia de enmiendas a la Carta Política.

La dificultad ha sido doble: (1) la Constitución de 1991, a diferencia de algunos textos fundamentales europeos de posguerra, no contiene cláusulas pétreas, es decir, disposiciones que escapan al poder de reforma del constituyente derivado; y (2) el artículo 241.1 superior le confiere competencia al Tribunal Constitucional únicamente para "Decidir sobre las demandas de inconstitucionalidad que promuevan los ciudadanos contra los actos reformatorios de la Constitución, cualquiera que sea su origen, sólo por vicios de procedimiento en su formación".

En la sentencia C-551 de 2003, con ocasión de la revisión de constitucionalidad de la Ley 796 de 2003, "Por la cual se convoca un referendo y se somete a consideración del pueblo un proyecto de reforma constitucional", la Corte modificó su precedente y analizó si el Congreso de la República había excedido sus competencias al momento de aprobar una ley que hacía parte de un proceso de reforma a la Carta Política, es decir, no se limitó, como antaño, a verificar la validez del procedimiento surtido por el texto normativo sometido a su examen.

15 ELSTER, JoN, Ulises y las sirenas, Estudios sobre racionalidad, precompromiso y restricciones, Barcelona, Fondo de Cultura Económica, 1989. 
El punto de partida del análisis del juez constitucional fue la clásica diferencia, creada en su momento por Sièyes ${ }^{16}$, entre poderes constituyentes originario y derivado. Así, mientras el primero no está sujeto a límites jurídicos, y comporta, por encima de todo, un ejercicio pleno del poder político de los asociados, el segundo se refiere a la capacidad que tienen ciertos órganos del Estado, en ocasiones con la consulta a la ciudadanía, para modificar una Constitución existente, pero dentro de los cauces determinados por ella.

La principal consecuencia de esta diferencia es la siguiente: el poder de reforma, que es poder constituido, no está autorizado para derogar o sustituir la Constitución, de la cual deriva su competencia. En consecuencia, le está vedado arrogarse funciones propias del poder constituyente, y por ello le está prohibido llevar a cabo una sustitución de la Constitución, no sólo por cuanto se estaría erigiendo en poder constituyente originario sino porque estaría minando las bases de su propia competencia.

Superado el debate acerca de la fundamentación teórica del control de constitucionalidad por vicios de competencia en materia de reformas al Texto Fundamental, la controversia se ha centrado en los siguientes aspectos: (1) la identificación y concreción de los "principios fundantes" de la Constitución de 1991; y (2) la construcción de un test que le permita al juez constitucional establecer cuándo se está ante una enmienda válida a la Carta Política y en qué casos se trata de una sustitución de esta.

\section{IDENTIFICACIÓN Y CONCRECIÓN DE LOS “ELEMENTOS DEFINITORIOS” DE LA CONSTITUCIÓN DE 1991}

El principal desafío asumido por la Corte Constitucional desde la adopción de la sentencia C-551 de 2003 ha sido identificar y concretar los denominados "elementos definitorios", "axiales" o "fundantes" de la Constitución de 1991, cuyo núcleo esencial escapa a la competencia del constituyente derivado.

Una de las razones que explican tal grado de dificultad estriba en las numerosas, y en ocasiones profundas, enmiendas que ha conocido el actual Texto Fundamental. A la fecha han sido adoptadas un total de cincuenta y dos reformas constitucionales.

El siguiente gráfico muestra que antes de la adopción de la sentencia C-551 de 2003 el Congreso de la República había aprobado diecisiete reformas constitucionales en un lapso de once años (promedio de 0,64 ) cuyo control eventual fue sólo por vicios de procedimiento, y luego de aquélla se han expedido hasta la fecha treinta y cinco enmiendas, esto es, en un lapso de diecisiete años (promedio de 2,05). 


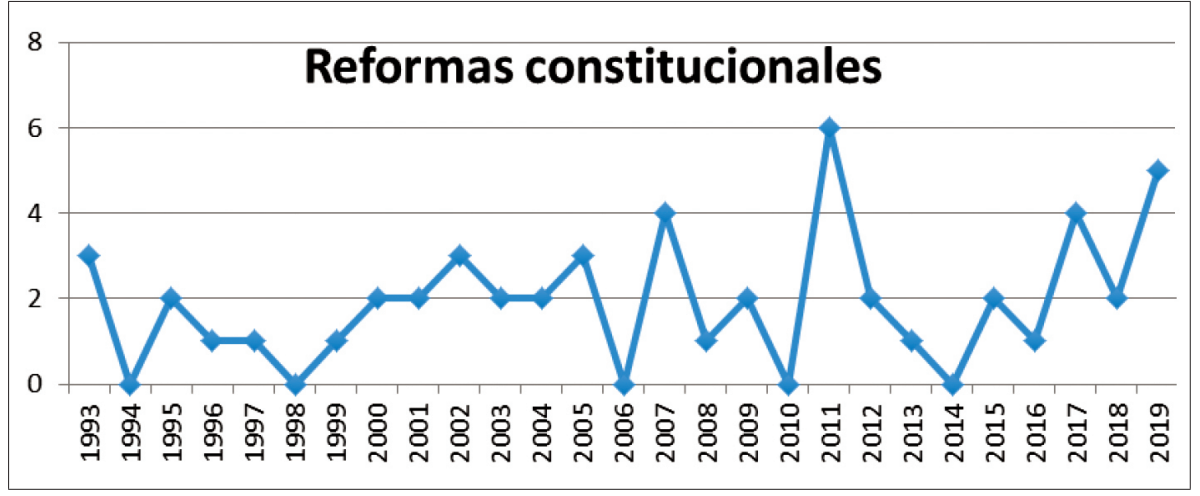

El diagnóstico pone de presente que, paradójicamente, la puesta en marcha de un control de constitucional por vicios de competencia de forma alguna ha conducido a mermar o atenuar la cantidad de reformas realizadas a la Carta Política. Todo lo contrario: su número ha aumentado, generándose así un fenómeno de hiperinflación constitucional y déficit legislativo, por ejemplo, en temas electorales. Además, tal proliferación de reformas constitucionales pareciera controvertir el clásico argumento según el cual el ejercicio del control de constitucionalidad por vicios de competencia conduce a petrificar el texto de la Carta Política.

En relación con los temas objeto de reforma, se tiene lo siguiente:

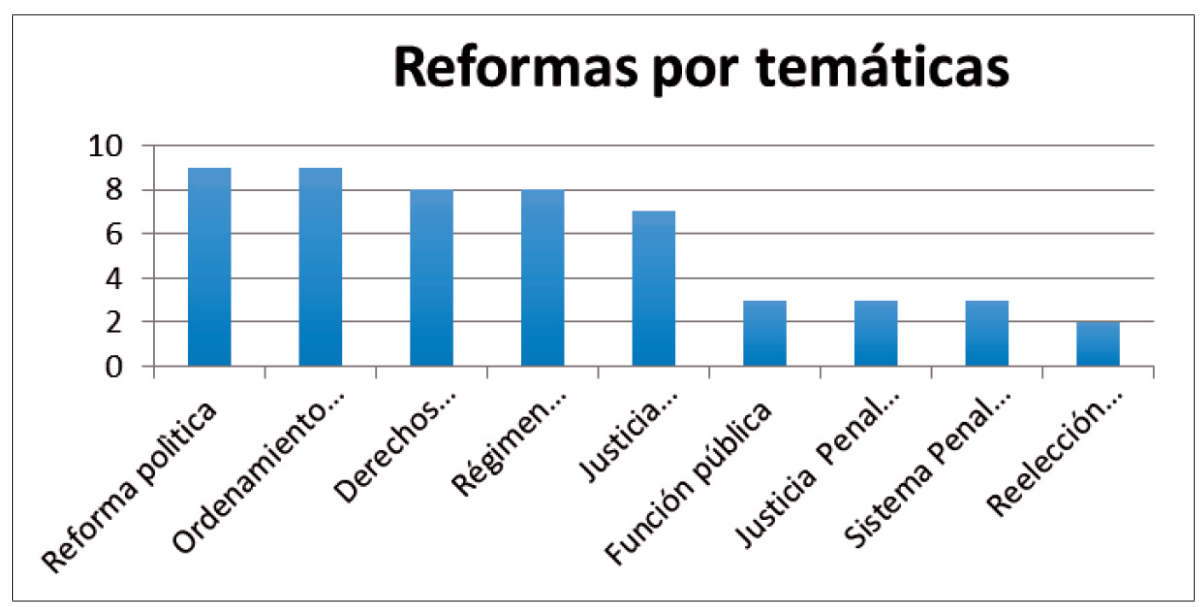

Del total de cincuenta y dos reformas constitucionales, nueve se relacionan con las reglas del sistema político colombiano (principalmente con el sistema electoral, el voto preferente, el sistema de bancadas, etcétera); igual número 
respecto del ordenamiento territorial, en especial en su dimensión económica (creación de numerosos distritos turísticos y aduaneros); ocho versan sobre el régimen económico (régimen de regalías, sistema general de participaciones, control fiscal, entre otros), en tanto que idéntica cantidad afectan directamente cláusulas de derechos fundamentales, es decir, un poco más de una sexta parte.

Tales enmiendas han introducido ajustes de mayor o menor calado, en temas tales como: extradición de nacionales, límites al derecho a la propiedad privada, régimen pensional, sostenibilidad fiscal y protección de los derechos económicos, sociales y culturales, límites a concesiones de amnistías, incorporación del Estatuto de Roma de la Corte Penal Internacional, doble instancia para aforados, entre otros.

Adicionalmente, en los últimos años, las reformas constitucionales relacionadas con la justicia transicional, presentaron un incremento (7), reflejo de las negociaciones entre el Gobierno Nacional y las FARC (en especial, la creación de un Sistema Integral de Verdad, Justicia, Reparación y Garantías de no Repetición y cláusulas de estabilidad del Acuerdo Final) en tanto que una tendría implicaciones respecto a futuros procesos de paz, en la medida en que limita la concesión de amnistías o indultos.

Adicionalmente, tres reformas constitucionales están relacionadas con la implementación de un sistema penal acusatorio; igual número con el régimen de la función pública y dos con la reelección presidencial.

Así las cosas, como se ha señalado, el grueso de las modificaciones a la Carta Política de 1991 versa sobre temas de estructura y funcionamiento del Estado: ordenamiento territorial, régimen económico, sistema político, reelección presidencial, función pública y sistema penal acusatorio, principalmente. Por el contrario, las enmiendas relacionadas directamente con la Carta de Derechos han sido relativamente escasas y puntuales.

En cuanto a los "ejes definitorios", la Corte Constitucional ha identificado, entre otros, los siguientes: el principio democrático, el principio de separación y equilibrio de poderes, el modelo del Estado social de derecho, el principio de legalidad, la garantía del juez natural, la autonomía e independencia judiciales, el mérito en la carrera administrativa y el deber internacional de perseguir y sancionar las graves infracciones al derecho internacional humanitario y a los derechos humanos ${ }^{17}$.

Una vez identificado un "eje definitorio" se deben concretar sus contenidos y alcances, lo cual implica desentrañar sus elementos definitorios, actividad que resulta compleja, por cuanto aquéllos suelen presentar una estructura de principio y no de regla. En otras palabras, no se trata de normas que prevean un supuesto fáctico y una consecuencia jurídica, sino de mandatos de optimización. De allí que sus contornos suelan ser imprecisos, abiertos, abstractos,

17 Para ver un análisis de esta evolución jurisprudencial, ver Ramírez Cleves, GonZalo, "La inconstitucionalidad de las reformas constitucionales...", op. cit. 
debiendo ser precisados recurriendo a distintas técnicas: origen y evolución histórica del principio, aportes del derecho comparado, antecedentes de los debates en la Asamblea Nacional Constituyente, instrumentos internacionales que hacen parte del bloque de constitucionalidad, entre otros.

A semejanza de Colombia, en Italia tampoco se ha elaborado una lista cerrada o definitiva de aquellos principios que se consideran "supremos", y por ende, inmodificables. Así por ejemplo, en dicho país se han calificado como fundamentales, los siguientes principios: la unidad de jurisdicción del Estado (fallo número 30 de 1971); el derecho a la protección constitucional (fallos números 98 de 1965, 232 de 1989 y 349 de 2007); el carácter laico del Estado (fallos números 203 de 1989, 259 de 1990, 13 de 1991, 421 de 1993 y 508 de 2000); el principio democrático (fallo número 30 de 1971); y la protección de los derechos inalienables (fallos números 183 de 1973, 170 de 1984, 232 de 1989, 73 de 2001, 348 de 2007 y 454 de 2006) ${ }^{18}$.

Autores como Ramírez sostienen las bondades de contar con un listado abierto e indeterminado de elementos fundamentales, por cuanto bien puede pasar que lo fáctico supere lo normativo ${ }^{19}$. Sin embargo, tal apertura termina generando espacios de incertidumbre, de amplia discrecionalidad judicial, en desmedro de las competencias del Congreso de la República, lo cual puede conducir a petrificar extensos espectros de una Constitución, en especial, relacionados con su estructura orgánica, tal y como ha pasado en Colombia (v. gr., administración de la Rama Judicial, tribunal de aforados, entre otros). De allí que, si ya se cuenta con un catálogo generoso de "elementos fundamentales", lo mejor sería no ampliarlo, salvo que una razón muy poderosa así lo demande, y emplear el test de sustitución de forma realmente excepcional, encuadrado dentro de un test de proporcionalidad.

\section{EL TEST DE SUSTITUCIÓN}

El reconocimiento de una competencia en cabeza de la Corte Constitucional para examinar si el constituyente derivado desbordó su competencia para reformar la Carta Política, comporta asumir un desafío mayor, cual es idear un método que permita: (1) alcanzar un equilibrio entre el principio democrático (i.e., voluntad de las mayorías, necesidad de cambio y prevención de acudir a mecanismos extraconstitucionales de reforma) y la salvaguarda de los derechos fundamentales (los llamados "cotos vedados" para los reformadores, en los términos de Pedro de Vega ${ }^{20}$ ); (2) determinar en qué casos se está ante

18 Luciani, Massimo, "Le contrôle de constitutionnalité des lois constitutionnelles en Italie", Les cahiers du Constitutionnel, París, 2009, p. 27.

19 Ramírez Cleves, Gonzalo, "La inconstitucionalidad de las reformas constitucionales...", op. cit.

20 De Vega, Pedro, La reforma constitucional y la problemática del poder constituyente, Madrid, Tecnos, 1985. 
una verdadera sustitución de un eje fundamental del Texto Fundamental de 1991; y (3) que dada su racionalidad, coherencia y transparencia, logre contrarrestar las clásicas críticas al subjetivismo de los tribunales constitucionales en la materia.

En la sentencia fundadora de la línea jurisprudencial (C-551 de 2003), la Corte precisó que para determinar si una reforma constitucional es en realidad una sustitución de la Constitución, no se puede partir de una comparación entre la disposición superior cuestionada y un artículo de determinado tratado, porque ello equivaldría a extraer los tratados del bloque de constitucionalidad para elevarlos a un rango supraconstitucional.

En la sentencia C-1200 de 2003, a pesar de tratarse de un fallo inhibitorio, la Corte consideró que la premisa mayor del juicio de sustitución debía estar conformada por una afectación del núcleo esencial de un principio definitorio y que no podía ser una norma de la actual Constitución.

La construcción dogmática del test de sustitución avanzó con la sentencia C-1040 de 2005, en la cual la Corte precisó que el juez constitucional debía realizar dos tareas específicas al momento de enfrentar tal examen: (1) establecer cuáles son los elementos esenciales que definen la identidad de la Constitución y (2) analizar cómo puede una reforma llegar a ser realmente una sustitución de la Constitución.

En la providencia C-303 de 2010, con ocasión del examen de una demanda de inconstitucionalidad contra la Reforma Política de 2009, la Corte hizo una acotación importante: no toda enmienda de la Constitución, por profunda que sea, configura necesariamente una sustitución de ella. De igual manera, se concretaron los tres componentes básicos del test de sustitución:

Una premisa mayor, consistente en la identificación de aquellos aspectos definitorios de la identidad de la Constitución que se suponen sustituidos por el acto reformatorio. Ello permite a la Corte establecer los parámetros normativos aplicables al examen de constitucionalidad del acto acusado. La premisa mayor es un enunciado específico, que no se limita a plantear los aspectos que, de manera general, tiene una determinada institución en el constitucionalismo contemporáneo, sino la forma particular como un elemento definitorio ha sido configurado en la Constitución colombiana y que, por consiguiente, hace parte de su identidad.

Una premisa menor, conformada por la interpretación que la Corte realice del contenido y alcance del acto reformatorio acusado.

Finalmente, una conclusión, que resulta de confrontar la premisa menor con la mayor, lo cual se traduce en la adopción de un fallo de exequibilidad simple, condicionada o inexequibilidad. 
IV. CASOS EN QUE LA PREMISA MAYOR

SON ESTÁNDARES INTERNACIONALES:

¿UNA SUPRACONSTITUCIONALIDAD NEGADA?

A partir de la sentencia C-225 de 1995, la Corte Constitucional acogió expresamente la figura del bloque de constitucionalidad, en tanto que técnica jurídica que permitiría armonizar los contenidos de dos artículos de la Carta Política contradictorios: el artículo 4 (supremacía constitucional) y el artículo 93 (prevalencia de algunos tratados internacionales). En dicho fallo, expresamente se rechazó todo atisbo de supraconstitucionalidad:

A partir de todo lo anterior se concluye que los convenios de derecho internacional humanitario prevalecen en el orden interno. Sin embargo, ¿cuál es el alcance de esta prevalencia? Algunos doctrinantes y algunos intervinientes en este proceso la han entendido como una verdadera supraconstitucionalidad, por ser estos convenios normas de ius cogens. Esto puede ser válido desde la perspectiva del derecho internacional puesto que, conforme al artículo 27 de la Convención de Viena sobre el derecho de los tratados, una Parte no podrá invocar las disposiciones de su derecho interno como justificación del incumplimiento de un tratado. Con menor razón aún podrán los Estados invocar el derecho interno para incumplir normas de ius cogens como las del derecho internacional humanitario. Pero, desde la perspectiva del derecho constitucional colombiano, esta interpretación debe ser matizada, puesto que la Constitución es norma de normas (CP art. $4^{\circ}$ ). ¿Cómo armonizar entonces el mandato del artículo 93, que confiere prevalencia y por ende supremacía en el orden interno a ciertos contenidos de los convenios de derechos humanos, con el artículo $4^{\circ}$ que establece la supremacía no de los tratados sino de la Constitución? [Énfasis agregado.]

A partir de entonces, pareciera zanjada la discusión en torno al lugar que ocupan los tratados internacionales sobre derechos humanos en Colombia, en el sentido de ubicarse en el mismo nivel que la Constitución. Con todo, algunos fallos proferidos por el Tribunal Constitucional en sede del test de sustitución contradicen tal afirmación. El ejemplo paradigmático es la sentencia C-579 de 2013, fallo proferido con ocasión de una demanda de inconstitucionalidad incoada contra algunos artículos del Acto Legislativo 01 de 2012, más conocido como "Marco Jurídico para la Paz".

Al momento de construir el test de sustitución, el juez constitucional construyó la premisa mayor en los siguientes términos:

El pilar fundamental reconocido en esta ponencia es el compromiso del Estado social y democrático de derecho de respetar, proteger y garantizar los derechos de la sociedad y de las víctimas a partir del cual se deriva (1) la obligación de investigar, juzgar y en su caso sancionar (2) las graves violaciones a los derechos humanos y (3) al derecho internacional humanitario: 
(1) La obligación de investigar, juzgar y en su caso sancionar, implica la realización de todos los esfuerzos posibles para investigar, juzgar y sancionar las graves violaciones a los derechos humanos y al derecho internacional humanitario. En este sentido, la investigación debe ser seria, imparcial, efectiva, cumplida en un plazo razonable y con la participación de las víctimas y la sanción deberá consistir en una pena proporcional y efectiva.

(2) Las graves violaciones a los derechos humanos reconocidas por la comunidad internacional son especialmente las siguientes: (a) las ejecuciones extrajudiciales, (b) las desapariciones forzadas, (c) la tortura; (d) el genocidio; (e) el establecimiento o mantenimiento de personas en estado de esclavitud, servidumbre o trabajo forzoso; (f) la detención arbitraria y prolongada; (g) el desplazamiento forzado; (h) la violencia sexual contra las mujeres y (i) el reclutamiento forzado de menores.

(3) Los delitos que tipifican graves violaciones a los derechos humanos y graves infracciones al derecho internacional humanitario a nivel internacional son: los crímenes de lesa humanidad, los crímenes de guerra y el genocidio [énfasis agregado].

Como puede advertirse con toda facilidad, la premisa mayor se encuentra construida, en una gran proporción, por normas internacionales convencionales y consuetudinarias, en tanto que la premisa mayor, es decir, el texto normativo sometido a control de constitucionalidad, lo constituye una reforma a la Carta Política ${ }^{21}$. Lo anterior, sin lugar a dudas, evidencia un supuesto de supraconstitucionalidad.

\section{EL TEST DE SUSTITUCIÓN FRENTE AL ACUERDO FINAL}

Los dos test de sustitución que la Corte Constitucional realizó en relación con normatividades claves para la implementación del Acuerdo Final (Actos Legislativos 01 y 02 de 2017) resultaron ser particularmente severos, lo cual no deja de ser paradójico tomando en cuenta: (1) la naturaleza transitoria de las regulaciones objeto de control; (2) que se trata de instrumentos al servicio de la paz; y (3) no contarse con cargos de inconstitucionalidad.

En la sentencia C-674 de 2017 la Corte examinó la constitucionalidad del Acto Legislativo 01 de 2017, "Por medio del cual se crea un título de disposiciones transitorias de la Constitución para la terminación del conflicto armado y la construcción de una paz estable y duradera y se dictan otras disposiciones". Se trataba de analizar, en pocas palabras, el corazón mismo del Acuerdo Final en materia de justicia transicional.

21 Sobre el tema de la supraconstitucionalidad, véase Ramelli, Alejandro, Diálogos entre la Corte Interamericana de Derechos Humanos y los jueces constitucionales latinoamericanos. Bogotá: Tirant lo Blanch, 2019, p. 50. 
El alto tribunal realizó un control de constitucionalidad integral sobre la regulación del Sistema Integral de Verdad, Justicia, Reparación y no Repetición (SVJRNR), conformado por la Comisión para el Esclarecimiento de la Verdad, la Convivencia y la no Repetición (CVE), la Unidad para la Búsqueda de Personas dadas por Desaparecidas (UBPD) y la Jurisdicción Especial para la Paz (JEP).

Para tales efectos, y por primera vez en su historia, la Corte efectuó un triple control de constitucionalidad, automático e integral, sobre una enmienda a la Carta Política:

- Control sobre vicios de procedimiento. Se examinó el acatamiento de los principios y normas que regulan el Procedimiento Legislativo Especial para la Paz (Acto Legislativo 01 de 2016);

- Control de conexidad. Consistente en revisar si los temas regulados en el Acto Legislativo 01 de 2017 guardaban un vínculo material con lo previsto con el Acuerdo Final; y

- Test de sustitución. La Corte examinó si los artículos que integran el Acto Legislativo 01 de 2017 comportaban una sustitución de uno o varios ejes fundamentales de la Constitución de 1991.

En materia de test de sustitución, el juez constitucional identificó los siguientes elementos esenciales de la Carta Política:

- Deber del Estado de investigar, juzgar y sancionar las graves violaciones de derechos humanos y las infracciones al DiH y de garantizar los derechos de las víctimas a la verdad, la justicia, la reparación y la no repetición;

- El principio de separación de poderes y el sistema de frenos y contrapesos al poder;

- La independencia judicial, como expresión del principio de separación de poderes, como garantía de la imparcialidad y neutralidad de los operadores de justicia en la resolución de conflictos, y como instrumento para la realización de derechos fundamentales;

- La supremacía de la Constitución como fundamento de los sistemas y procedimientos de aseguramiento de la Carta Política como norma de normas;

- El principio democrático, el principio de legalidad, el derecho al debido proceso, y en particular, la garantía del juez natural.

Como resultado de la aplicación del test de sustitución, si bien la guardiana de la Constitución declaró ajustados al Texto Fundamental la mayoría de artículos de la reforma constitucional, hizo once declaratorias de inexequibilidad, entre 
ellas la más cuestionable, referente a la exclusión de los civiles no agentes del Estado, del ámbito de competencia de la JEP.

En la sentencia C-630 de 2017, el tribunal constitucional adelantó igualmente un triple control de constitucionalidad, en este caso respecto al Acto Legislativo 02 de 2017, "Por medio del cual se adiciona un artículo transitorio a la Constitución con el propósito de dar estabilidad y seguridad jurídica al acuerdo final para la terminación del conflicto y la construcción de una paz estable y duradera".

Es este caso, los ejes definitorios, que conformaron la premisa mayor del test de sustitución, fueron:

- la paz;

- el principio democrático;

- la separación de poderes; y

- la supremacía de la Constitución.

A pesar de que la Corte consideró que el Acto Legislativo 02 de 2017 superaba el test de sustitución, condicionó severamente la exequibilidad del mismo, mediante numerosas declaraciones interpretativas las cuales, en la práctica, debilitan notoriamente el llamado "blindaje jurídico" del Acuerdo Final. Así por ejemplo, todos los compromisos asumidos en aquél son considerados en términos del obligaciones de medio y ninguna de resultado; se facultó a las autoridades públicas para elegir los medios que estimen convenientes para cumplir lo acordado, e igualmente se confundieron los test de validez y conexidad.

A mi juicio, la realización del test de sustutición adelantado sobre los actos legislativos 01 y 02 de 2017, referentes a la implementación del Acuerdo Final, muestran que la Corte acogió el siguiente modelo de relaciones entre la Carta Política y aquél:

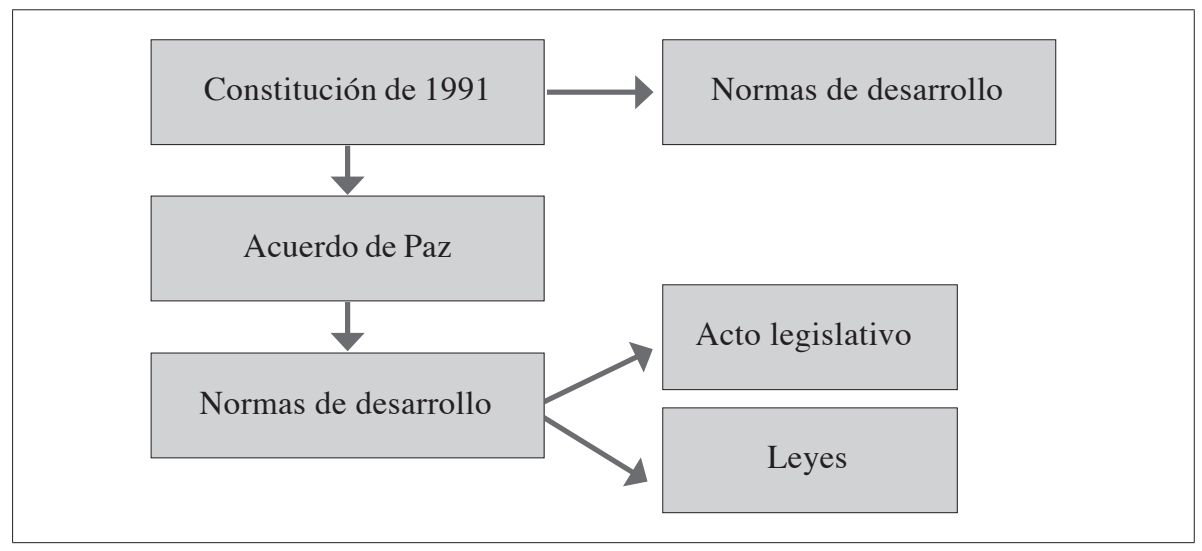


Según este modelo, la validez del Acuerdo Final se encuentra supeditada a su conformidad con la Constitución. De tal suerte que las llamadas normas de implementación deberán guardar simplemente una conexidad con el Acuerdo de Paz, pero su validez dependerá de su ajuste a la Carta Política.

En otras palabras: al momento de realizar el test de sustitución sobre el Acto Legislativo 01 de 2017 (norma de implementación del Acuerdo Final), la Corte construyó la premisa mayor únicamente con los ejes definitorios del Texto Fundamental de 1991 ( $v . g r$., principio del juez natural), sin tomar en cuenta el texto del Acuerdo de Paz, y sin buscar una armonización entre ambas normatividades; tan sólo se aludió, de manera muy general, al eje definitorio de la paz.

Por el contrario, son escasos los fallos de la Corte que parecen haberse inclinado por un modelo o paradigma más armónico entre la Constitución y el Acuerdo Final, como sería el siguiente:

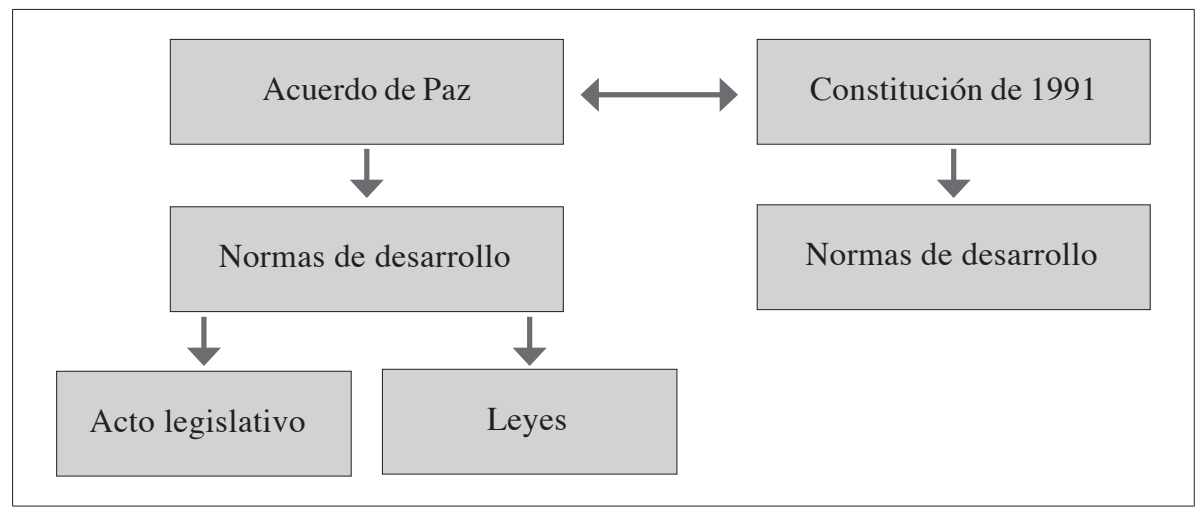

$\mathrm{Al}$ respecto, en la sentencia C-224 de 2017, referente al examen del decreto ley mediante el cual se creó la Comisión Nacional de Garantías, la Corte indicó:

El juez constitucional debe analizar si las normas de ejecución mediante las cuales se crean estas nuevas instituciones se ajustan a la Constitución, labor que debe apuntar a encontrar un delicado equilibrio entre la defensa judicial de la Carta Política y el cumplimiento de lo acordado, en tanto que manifestación del derecho fundamental a la paz [énfasis agregado].

Así las cosas, y contrario a lo que indicaría el sentido común, el control de constitucionalidad realizado sobre la legislación para la paz en Colombia terminó siendo más severo y complejo que aquel que durante décadas se llevó a cabo para regular la guerra (estado de excepción). En efecto, no sólo se adelantaron tres controles sobre los actos legislativos de implementación, sino que aquel de sustitución fue llevado a cabo de forma oficiosa, es decir, 
sin siquiera existir cargos de inconstitucionalidad, lo cual abre las puertas a las críticas sobre el activismo judicial.

\section{CONCLUSIONES}

Primera: El ejercicio de un control constitucional por vicios de competencia se inscribe en uno de los debates más candentes e interesantes del derecho constitucional contemporáneo: la tensión que se presenta entre, por una parte, el principio democrático (regla de la mayoría) y la necesidad de ajustar un texto normativo a las cambiantes realidades económicas, sociales, políticas y culturales de una sociedad, y, por otra, la exigencia de preservar la esencia de lo que constituye uno de los mayores valores de nuestra civilización occidental: la construcción de un Estado social de derecho fundado sobre el respeto por la dignidad humana y los derechos fundamentales.

Segunda: Ante la inexistencia de cláusulas pétreas o inmodificables en la Constitución de 1991, la Corte Constitucional ha considerado, desde la sentencia C-551 de 2003 hasta el presente, que existen ciertos "ejes definitorios", que configuran la esencia o encarnan el espíritu de la actual Carta Política, y que, por ende, escapan al ámbito de competencia del constituyente derivado. Tal afirmación de principio ha conducido al diseñar una metodología que permite determinar cuándo se está en presencia de una reforma constitucional válida y en qué supuestos se presenta una extralimitación o un desbordamiento del poder de reforma.

Tercera: El test de sustitución se estructura sobre el clásico silogismo jurídico: premisa mayor, premisa menor y conclusión. La complejidad consiste en que, a diferencia del control de constitucionalidad que se realiza sobre las leyes, donde la premisa mayor es una disposición del Texto Fundamental, en este caso se trata de algo mucho más abstracto, y en cierta medida, inaccesible: un "elemento definitorio" de la Constitución de 1991. A lo largo de su jurisprudencia, la Corte ha venido calificando y delimitando algunos de esos ejes fundamentales, tales como: la cláusula del Estado social de derecho, el principio de separación de poderes, el principio democrático, entre otros. Se ha tratado de una construcción casuística, con las ventajas e inconvenientes que suelen acompañar esta clase de metodologías.

Cuarta: La vía por la cual la Corte asume el conocimiento de la validez de una reforma constitucional -salvo el caso de los referendos constitucionales- ofrece no pocas dificultades e incertidumbres. Por tratarse de un control rogado, y no automático, sólo puede asumir competencia cuando un ciudadano, actuando dentro del año siguiente a la expedición de la enmienda constitucional, logre configurar uno o varios cargos de inconstitucionalidad por sustitución de la Constitución, lo cual exige un grado de conocimiento amplio de la jurisprudencia de la Corte. En otras palabras, difícilmente un ciudadano lego en la materia puede acceder a la justicia constitucional. 
Quinta: La puesta en marcha de un control de constitucionalidad por vicios de competencia no ha comportado una reducción del número de enmiendas al Texto Fundamental. Paradójicamente, luego de la adopción de la sentencia C-551 de 2003, el número de reformas constitucionales no sólo ha aumentado, sino que son las más profundas e importantes que ha conocido la Constitución de 1991 desde su expedición (reforma política, reelección presidencia, justicia transicional, entre otras). De allí que no haya tenido lugar el fenómeno de "petrificación", al que tanto aluden los especialistas en el tema.

Sexta: Las principales críticas que se escuchan a la realización de un test de sustitución son las siguientes: (1) en materia de reformas constitucionales, la Carta Política de 1991 sólo prevé la realización de control por vicios de procedimiento; (2) la distinción entre reformar y sustituir la Constitución es subjetiva y política; y (3) se trata de una tesis que conduce a imponer la visión de la Constitución que tenga la Corte, sobre aquella del Congreso.

Séptima: El ejercicio del control de constitucionalidad por vicios de competencia exige que los jueces apliquen el principio de autocontención (self restraint), con miras a: (1) permitir que la Constitución, entendida como un "ser viviente", pueda ajustarse a los cambios sociales, políticos, económicos y culturales; (2) evitar que las mayorías prefieran acudir a vías extraconstitucionales para reformar, o incluso destruir, la Carta Política; y (3) impedir que el juicio de sustitución sea percibido por los ciudadanos como el ejercicio de un control material, o incluso político, sobre las reformas a la Constitución.

Octava: La construcción de una dogmática sobre el control de constitucionalidad relativo a vicios de competencia es un proceso inacabado. Hace unos años, dos magistrados del tribunal constitucional ${ }^{22}$ salvaron sus votos en relación con el auto número 368 del 26 de agosto de 2015, mediante el cual se determinó la inviabilidad de decretar la suspensión provisional de la aplicación de los artículos 14, 15, 16, 17, 18 y 19 del Acto Legislativo 2 de 2015. Para los disidentes, la Corte sí cuenta con dicha competencia, la cual debe ser ejercida de forma excepcional (principio del self restraint), con fundamento en lo siguiente: (1) se trata de un corolario de la competencia de la Corte para conocer sobre vicios de competencia en materia de reformas constitucionales; (2) configura una aplicación de la teoría de los poderes implícitos; y (3) existen algunos ejemplos similares en el derecho comparado.

Novena: En un escenario hipotético, un juicio histórico sobre el ejercicio del control de constitucionalidad sobre vicios de competencia puede resultar agridulce: unos jueces, activos en la defensa de los fundamentos del Estado social de derecho, pueden evitar que una sociedad, sumida en un estado de crisis económica o social profunda, caiga en la tentación, en palabras de Duverger, de abrazar un régimen político "cesarista" o autocrático; al mismo tiempo, en 
otro escenario, un tribunal integrado por magistrados alejados de la defensa de los valores democráticos puede dar al traste con reformas constitucionales progresistas $(v . g r$, igualdad entre parejas del mismo sexo, protección de minorías étnicas, etcétera). A pesar de todos los riesgos, teóricos o reales, que implica contar en una democracia con dicho instrumento de control judicial, todo parece indicar que su inexistencia comporta una amenaza aún mayor para la preservación de aquélla.

\section{BIBLIOGRAFÍA}

\section{Libros y artículos especializados}

ACKerman, B. Constitutional Politics. Constitutional Law, The Yale Law Journal, n. ${ }^{\circ}$ 99, 1989.

Amar, Aкнl. America's Constitution: A Biography, Nueva York, Random House, 2006.

AA. vv. Reflexiones jurídicas sobre el proceso de paz, Bogotá, Universidad Externado de Colombia, 2017.

Benítez Rojas, Vicente. Constitución popular, no judicial. Una teoría democrática del control de constitucionalidad de las reformas a la Constitución en Colombia, Bogotá, Temis-Universidad de la Sabana, 2014.

Benítez Rojas, Vicente. Jueces y democracia: entre Ulises y los cantos de sirenas, Revista de la Facultad de Derecho y Ciencias Políticas, 2012.

De Vega, Pedro. La reforma constitucional y la problemática del poder constituyente, Madrid, Tecnos, 1985.

Diva Rai. Golaknath, I. C. v State of Punjab (1967): Overview and Analysis, 2019.

ELSTER, Jon. Ulises y las sirenas, Estudios sobre racionalidad, precompromiso y restricciones, Barcelona, Fondo de Cultura Económica, 1989.

Hamilton, Alexander, Madison, James y Jay, John. El Federalista, México, Fondo de Cultura Económica, 1994.

Kaboglu, Ibrahim. "Le contrôle jurisdictionnel des amendements constitutionnels en Turquie", Les cahiers du Constitutionnel, París, 2009.

Luciani, Massimo. "Le contrôle de constitutionnalité des lois constitutionnelles en Italie", Les cahiers du Constitutionnel, París, 2009.

Ramelli, Alejandro. Diálogos entre la Corte Interamericana de Derechos Humanos y los jueces constitucionales latinoamericanos. Bogotá: Tirant lo Blanch, 2019.

Ramírez Cleves, Gonzalo. Los límites a la reforma constitucional y las garantías-límites del poder constituyente: los derechos fundamentales como paradigma, Bogotá, Universidad Externado de Colombia, 2003. 
Ramírez Cleves, Gonzalo. Límites a la reforma constitucional en Colombia: el concepto de Constitución como fundamento de la restricción, Bogotá, Universidad Externado de Colombia, 2005.

Ramírez Cleves, Gonzalo. "La inconstitucionalidad de las reformas constitucionales en Colombia: tensión entre democracia de mayorías y democracia constitucional", en $\mathrm{La}$ reforma constitucional y su problemática en el derecho comparado, Bogotá, edit. VLex, 2017.

Roznai, Yaniv. "Unconstitutional constitutional amendments: The Limits of Amendment Powers, Cambridge, 2017.

Roznai, Yaniv. "Unconstitutional constitutional amendments. The migration and success of a constitutional idea", American Journal of Comparative Law, vol. 61, n. ${ }^{\circ}$ 3, 2013.

Sieyes, Emmanuel. ¿Qué es el tercer estado?, París, 1975.

\section{Jurisprudencia constitucional colombiana}

Sentencia C-551 de 2003

Sentencia C-1200 de 2003

Sentencia C-1040 de 2005

Sentencia C-303 de 2010

Sentencia C-249 de 2012

Sentencia C-373 de 2016

Sentencia C-630 de 2017

Sentencia C-674 de 2017

\section{Jurisprudencia extranjera}

Corte Suprema de la India, asunto Golaknath vs. State of Punjab sentencia del 27 de febrero de 1967 (1967) AIR 1643, 2 mil SCR (2) 76.

Corte Suprema de la India, asunto Kesavaranda Bharati vs. State of Kerala, sentencia del 24 de abril de 1973, (1973) 4 scC 225.

Corte Suprema de la India, sentencia del 15 de octubre de 2015, writ petition (Civil), n. ${ }^{\circ}$, 2015. 